\title{
Francisco de Quevedo y Antonio Sancho Dávila y Toledo Colonna, III marqués de Velada*
}

\author{
ISABel PÉREZ CUeNCA \\ Universidad San Pablo-CEU
}

No huuo señor en España, que con extraordinarias demostraciones no le honrasse; y aunque pudiera nombrar a muchos de los que se señalaron en estimarle, es escusado el dilatarme, quando en dos solos de los mayores desta Monarquía, como en dos polos, se boluía la gloria deste varón esclarecido. El vno fue don Pedro Girón, duque de Ossuna [...]. Y el otro fue don Antonio Iuan Luis de la Cerda, duque de Medina-Celi, y de Alcalá.

(Tarsia, 1988: 45-46)

Los años últimos del reinado de Felipe III y los diez primeros de su sucesor, Felipe IV, constituyen una complicada etapa para Francisco de Quevedo y sus posibilidades de medrar, al amparo de los poderosos clanes nobiliarios que se disputan el favor y no son favorables sus posibilidades de medrar al amparo de los poderosos clanes nobiliarios que se disputan el favor real. La caída en la privanza primero del duque de Lerma y luego de su hijo, el duque de Uceda, y la llegada al valimiento de Baltasar de Zúñiga seguido de su sobrino, el conde de Olivares, son acontecimientos que se

* Este trabajo se ha realizado en el marco de los proyectos FFI2015-65779-P y HAR2015-68946-C3-1-P, financiados por el Ministerio de Economía y Competitividad del Gobierno de España y el Fondo Europeo de Desarrollo Regional (FEDER) desde el 01/01/2016 hasta el 31/12/2019. 
manifiestan en una lucha de facciones a la que no es ajena nuestro escritor. Teniendo en cuenta el enfrentamiento entablado entre los Sandoval, Toledo y otros grandes con el clan de los Guzmán propongo leer la conocida carta escrita por Quevedo al marqués de Velada en el año 1624.

Las cartas de Francisco de Quevedo ofrecen informaciones muy variadas sobre la vida y la obra del autor y sobre aspectos de otra índole, como son la política interior y exterior o las campañas militares. Pero también leemos en ellas ricas y variadas referencias acerca de muchos individuos coetáneos al autor, ya sean nobles o sujetos ligados a la Corte y al servicio de la monarquía con mayor o menor relevancia en la política y Corte del periodo. Al igual que sucede con otras — por ejemplo las de Almansa y Mendoza-, muchas de ellas se escriben con la decidida voluntad de informar, y son estas de un interés mayor para ayudar a comprender las redes informativas creadas en torno al escritor y los vínculos establecidos por él con los varios sujetos que en ellas se mencionan o con los que mantiene correspondencia ${ }^{1}$.

Mi intención en este momento no es desenmarañar la tupida red de informadores o informados tejida a su alrededor, ni tampoco delimitar y definir la clase de relación que establece con los grupos de poder y oposición, ese trabajo queda para mejor ocasión; ahora me centraré exclusivamente en uno de los grandes títulos caídos en desgracia con la llegada de Zúñiga y Guzmán a la privanza, el marqués de Velada. Se trazará la línea que une a ambos y que se remonta a los tiempos del rey Prudente, Felipe II y que, al menos, se prolonga hasta principios de 1624, cuando el rey planeta, Felipe IV, emprende la jornada a Andalucía descrita, en sus primeros días de viaje, por Quevedo en una jocosa y festiva carta dirigida a Velada; sin despreciar la posibilidad de que los contactos entre ambos se mantengan pasada esa fecha. Con ello se pretende ahondar en la facción política en la que se ubica Quevedo en los años que se produce el cambio de reinado y la llegada a la privanza de Olivares $^{2}$.

1 La correspondencia que Quevedo sostiene con el duque de Medinaceli es paradigmática de ese afán informativo que sobresale en buena parte del epistolario del escritor (Pérez Cuenca, 2016), lo mismo podemos decir del conjunto autógrafo que se conserva remitido a Sancho de Sandoval (Quevedo, 2009) y en gran medida este aspecto es el más destacado del conjunto anotado por Crosby (Quevedo, 2005) correspondiente al periodo final de la vida del escritor (1639-1645).

2 Del triángulo formado por Quevedo, Velada y Olivares ya se trató en Pérez Cuenca y Campa Gutiérrez (2017). 
Comenzaré con una revisión de las relaciones familiares del escritor y del II marqués de Velada con las casas reales, tomando como punto de partida para el primero la documentación reunida por Riandière (1986, 1992 y 2010), Crosby y Jauralde (1992); para Gómez Dávila han sido fundamentales los estudios de Martínez Hernández (2004a ${ }^{3}$ y 2004b). También han sido de enorme utilidad para rastrear tanto a los familiares de Quevedo como a los Dávila los tomos sobre las casas reales de Felipe II, Felipe III y Felipe IV preparados por Martínez Millán y Fernández Conti (2005), Martínez Millán y Visceglia (2007 y 2008) y Martínez Millán y Hortal Muñoz (2015). Terminaré realizando un somero repaso de algunos personajes citados en el único documento conservado que pone en directo contacto a Francisco de Quevedo con Antonio Sancho Dávila, III marqués de Velada, la carta ya citada sobre el viaje de Felipe IV a Andalucía (Quevedo, 1993), donde se hace referencia a algunos personajes que creo importante contextualizar en el marco político del momento.

La documentación que registran todas las obras mencionadas dibuja un mismo perfil de ambos clanes, los Quevedo y los Velada cada uno de acuerdo al estrato social que le corresponde. Unos y otros son criados al servicio de reyes, príncipes e infantes desde los tiempos de Felipe II y establecen lazos familiares con otros miembros de su mismo entorno; esas uniones coadyuvan a consolidar, reforzar y mejorar sus estatus y a ampliar sus influencias, control y poder, además de disfrutar de prebendas y mercedes.

Gonzalo de Rueda, padre de Felipa de Espinosa, bisabuelo de Quevedo del lado materno, probablemente fue varlet de corps - oficial de la caballería - de la casa de Borgoña, al menos en 1571 (Martínez Millán y Fernández Conti, 2005: 399). Sabemos que ocupó el puesto de aposentador y guardadamas de la princesa de Portugal, doña Juana de Austria, hermana de Felipe II, casada con el príncipe don Juan y madre del rey don Sebastián, muerto en Alcazarquivir. La responsabilidad de su cargo implicaba cierta cercanía con la reina, pues era el encargado de su alojamiento y el de su séquito, de la provisión de leña y carbón, del acomodo del mobiliario, de las comidas, limpieza, dignidad y compostura de las damas que estaban al servicio de la reina (López Ruiz, 2008: 157).

Gonzalo de Rueda casó a su hija con otro criado real, Juan Gómez de Santibáñez, quien fue contino de Castilla desde el 29 de abril de 1566,

3 Puede consultarse en línea la tesis doctoral, precedente de este libro, <http:// eprints.ucm.es/4607> [consultado el 15.09.2018]. 
cargo que desempeñó hasta su muerte. El contino pertenece a las élites del reino, su misión es difícil de definir, es un servidor del rey con la obligación de permanecer en la Corte de forma continuada ${ }^{4}$. También estuvo como aposentador de palacio al servicio de María de Austria, emperatriz y reina de Bohemia (Martínez Millán y Fernández Conti, 2005:190). López Ruiz (2008: 158) añade que fue escribano de cámara ${ }^{5}$, razón ésta por la que viajó a Austria con la emperatriz Ana; también — como su padre- desempeñó los cargos de guardadamas y de aposentador de palacio de la reina doña Ana a partir de 1570 (Riandière, 2010: 101), además fue familiar del santo oficio.

El matrimonio Gómez de Santibánez y Espinosa tuvo dos hijas, Margarita de Espinosa y María de Santibánez, tía y madre de Francisco de Quevedo, que a su vez contrajeron matrimonio con Juan de Santoyo y Nevares y Pedro Gómez de Quevedo, emparentando de esta forma con otras dos familias de criados reales: Los Villegas y los Santoyo, con lo que se ensancha su círculo familiar y de influencia. Recuérdese que a través de la familia Villegas establecen lazos con Agustín de Villanueva — este casó con Ana Díez de Villegas, pariente cercana de María Sanz de Villegas, abuela por la rama paterna de Francisco de Quevedo-, quien ocupará altos cargos con Felipe III; la carrera en el funcionariado de la Monarquía

4 Acerca del oficio de contino, leáse Martínez Millán y Ezquerra Revilla (2002), además incluyen los nombres de aquellos personajes que desempeñaron este oficio, entre los que se encuentran el abuelo de Quevedo y un Santoyo.

5 Explican Martínez Millán y Trápaga Monchet $(2015: 337)$ que el oficio de escribano de cámara cristaliza en el reinado de Felipe III, en 1608, aunque aparece en la casa de Castilla de Isabel la Católica, «donde se ocupaba del guardarropa y de las habitaciones de uso cotidiano con la asistencia de un pequeño grupo de criados: ayudas de cámara, reposteros, un repostero de cera, costureras... Sin embargo, la irrupción del ceremonial borgoñón relegó al escribano de cámara a la casa de Castilla del emperador (compartido con su madre) [...]. También existió en la casa de Castilla del príncipe Felipe hasta que se le impuso la casa de Borgoña en 1548 [...]. En la planta de la casa que se puso al príncipe Felipe [III] en 1585, el cargo aparecía de nuevo». Téngase en cuenta que, como explica Martínez Hernández (2016: 53), «con el nombre de real cámara, cámara del rey o simplemente cámara, se identificaba el espacio físico y simbólico más inmediato a la persona del monarca, aquel que acogía su privacidad, y, por tanto, semioculto y restringido. Lo conformaba una sucesión de espacios — articulada en torno a un sistema de círculos concéntricos - cuya proximidad o lejanía al núcleo central (alcoba o dormitorio real) determinaba la importancia o irrelevancia de quienes transitaban por ellos». Léanse también las páginas siguientes donde se explica la regulación y funcionamiento de la cámara real (53-61); para su evolución y transformación en el siglo XVII remito a Martinéz Millán y Trápaga Monchet (2015). 
es continuada por sus hijos Jerónimo de Villanueva Díez de Villegas, el cual ascenderá hasta los puestos más preeminentes, llegando a convertirse en la mano derecha del valido de Felipe IV, y Agustín de Villanueva Díez de Villegas, este fue Justicia de Aragón y para finales del reinado (1662) obtuvo el título de marqués de Villalba ${ }^{6}$.

Los Santoyo - familia con la que emparenta Quevedo gracias al casamiento, celebrado en 1587, de su tía Margarita de Espinosa con Juan Santoyo de Nevares - también sirven a la monarquía desde los tiempos de Felipe II en puestos diversos. Francisco de Santoyo fue probablemente el padre del tío político de Quevedo y de otros tres hijos (Francisco de Nevares y Santoyo, Juan Ruiz de Velasco y Sebastián de Santoyo), todos ellos de la cámara del rey - ayuda de cámara, contino de Castilla, contador de cruzada y contador al servicio de María de Austria, reina de Bohemiasegún se documenta en Martínez Millán y Fernández Conti (2005: 421)7. Sobre los cargos que ocuparon varios miembros de esta familia y cómo se sucedieron en ellos en la cámara de Felipe II se informa, a su vez, en Martínez Millán y Trápaga Monchet:

Durante el reinado de Felipe II, Juan Ruiz de Velasco y su antecesor, Sebastián de Santoyo, ambos ayudas de cámara, habían ejercido un puesto similar [al de secretario de cámara, que no se fundó hasta el reinado de Felipe III], pero solo tuvieron "cuenta con la mesa de despacho y las llaves de los escritorios, algunos gastos secretos y dar las audiencias" [...]. Al morir Sebastián de Santoyo, le sucedió su hijo, Francisco, como ayuda de cámara. A su vez, éste fue sustituido por Juan Ruiz de Velasco. Una vez que murió el "Rey Prudente", Velasco quedó sin cargo y pasó a la secretaría de la reina y después a la Cámara de Castilla (2015: 333).

El cuñado de Margarita de Espinosa, Juan Ruiz de Velasco, fue uno de los pocos criados que permaneció en la cámara de Felipe II en los días

6 Como se apunta en el Diccionario biográfico español, los Villanueva fueron una familia de burócratas al servicio de la administración central de la monarquía, véanse las semblanzas que traza Juan Francisco Baltar Rodríguez y José María Lahoz Finestres de Jerónimo y de Agustín de Villanueva y Díez de Villegas, respectivamente, hijos ambos de Agustín de Villanueva, secretario del Consejo de Aragón y protonotario. También véase Baltar Rodríguez (2000).

7 No menciono los puestos de otros Santoyo aquí registrados, solo los que creo que corresponden al padre y hermanos del marido de Margarita de Espinosa. 
de su agonía junto a Fernando de Toledo, Cristóbal de Moura, Enrique de Guzmán ${ }^{8}$ y algún otro ayuda de cámara.

Por último recordar que el escritor madrileño también estuvo emparentado con los Alderete o Aldrete a través de su hermana Margarita, quien contrajo matrimonio con Juan de Alderete, caballero de la orden de Santiago y caballerizo de su majestad. De este enlace nacerán los únicos sobrinos de Quevedo, Juan y Pedro. Estos, a causa de su temprana orfandad, quedaron a cargo de un tío, hermano de Juan de Alderete, de nombre Martín Carrillo y Aldrete, hombre de iglesia:

Don Martín Carrillo y Aldrete, colegial del mayor del arçobispo en la vniuersidad de Salamanca, inquisidor de Valladolid, y después de la suprema y general inquisición de estos reynos; y auiéndole nombrado su magestad por visitador de la Chancillería, y Audiencia Real de la Nueva España y demás tribunales, que residen en la ciudad de México [...], bolviendo a España [...] su magestad le nombró por obispo de Ouiedo y luego de Osma y vltimamente por arçobispo de Granada (Tarsia, 1988: 3v-4r).

Puede observarse que las diferentes familias que confluyen en el árbol genealógico de Quevedo, tanto en las ramas troncales como en las adyacentes, estuvieron al servicio de reyes, emperatrices, príncipes e infantes, desempeñando cargos que implican un cierto contacto y cercanía con sus señores, durante los reinados de Felipe II y Felipe III. Cuando revisamos los estudios sobre las casas reales de los reinados de los tres Felipes, observamos que la aparición de los apellidos Villegas, Quevedo, Santoyo, Ruiz de Velasco y Aldrete o Alderete es recurrente en las relaciones de criados que allí se publican y, aunque no tenemos dato alguno que nos permita vincular a varios de estos personajes con la familia del escritor, creo relevante señalar las coincidencias de los apellidos.

8 Fernando de Toledo, hermano del marqués de Velada, disfrutó del favor de Felipe II quien le premió, tras servir en Italia, Flandes y Portugal, al acompañarle a Inglaterra en 1554 y, desde 1560, convertido en uno de sus criados más próximos, le nombró gentilhombre de su cámara (Martínez Hernández, 2004a: 133-134). Cristóbal de Moura, marqués de Castel Rodrigo, fue sumiller de corps con Felipe II y amigo de Gómez Dávila desde los tiempos de la Academia del duque de Alba. Enrique de Guzmán, hermano del marqués de las Navas y, por tanto, primo de Velada. Todos tres con el marqués de Velada formaron el grupo de consejeros más cercanos a Felipe II. 
Sin embargo hemos considerado ampliar la información que conocemos sobre la familia Santoyo como muestra del entramado familiar resultante de lo que, sin duda, fue una meditada política matrimonial llevada a cabo por la rama materna del escritor, la de los Santibáñez-Espinosa. Son seis los Santoyos, además de Juan Ruiz de Velasco, los que estuvieron tanto al servicio de la casa de Borgoña como al de la casa de Castilla, ocupando puestos de ayuda de cámara, costiller ${ }^{9}$ y contino, al menos desde los años 1554 a 1598.

Uno de ellos fue Juan de Santoyo Nevares, de quien se documenta que fue ayuda de cámara de la casa de Borgoña al menos entre 1588 y 1598, año de la muerte de Felipe II y, tras ella, de su jubilación. Fue hijo de Francisco Santoyo, contino y contador de la cruzada y hermano de Francisco Santoyo, ayuda de cámara también, quien disfrutó de una escribanía mayor de rentas en Canarias. Además de los seis ayudas de cámara que acompañaron al rey Felipe II en la jornada de Tarazona del año 1592, tres llevan el apellido Santoyo: Francisco, Sebastián y Juan, quizás este último sea el marido de Margarita de Espinosa (Martínez Millán y Fernández Conti, 2005: II, 822, 421 y 422$)^{10}$.

Gómez Dávila y Toledo, II marqués de Velada (1541-1616), fue el hijo primogénito de Sancho Dávila y Juana Enríquez de Toledo, hermana de María Enríquez de Toledo, duquesa de Alba. El padre muere cuando Gómez cuenta con tan solo cinco años, convirtiéndose entonces en el heredero y sucesor del I marqués de Velada, su abuelo, Gómez Dávila, el Viejo $^{11}$. Los lazos familiares con la casa de Alba se van a estrechar por esta razón, ya que él y sus hermanos quedan bajo la protección de su tío, el III duque de Alba, Fernando Álvarez de Toledo, «mayordomo mayor, [el cual] se había convertido en 1548 en el máximo referente del control de la gracia y patronazgo en la Corte, hecho que venía a reforzar su posición política, reafirmada tras la muerte del todopoderoso secretario del

9 Oficio de la casa de Borgoña equiparable al de gentilhombre de la casa, que acompañaba a su majestad cuando iba a la capilla, cuando iba a dar gracias y cuando asistía a la entrada de los embajadores en la primera audiencia. También tenía obligación de acompañar al rey cuando salía a campaña con dos caballos a su costa (Autoridades).

10 Registro en un anexo una síntesis de la información recopilada acerca de la familia de Quevedo y de los II y III marqués de Velada.

11 Gómez Dávila, el Viejo, fue recompensado por Felipe II con el marquesado de Velada en 1557, este fue el primer título que otorgó Felipe II una vez llegado al trono (Martínez Hernández, 2004a: 63). Para los orígenes del linaje véanse las pp. 39-63. 
emperador don Francisco de los Cobos» (Martínez Hernández, 2004a: 77). El joven Dávila ha de recibir con premura una educación acorde a su condición de heredero, que se desarrolló bajo la supervisión de su madre y abuelo y con el apoyo y tutela del de Alba. Por intercesión de Álvarez de Toledo se integran sus hermanos y él en la casa del príncipe don Carlos:

La llegada [a la casa del príncipe] de Gómez Dávila y sus hermanos Fernando y Diego se produjo estando ya la Corte de don Carlos en Valladolid, bajo el gobierno de la Princesa doña Juana, regente del reino durante la ausencia de su hermano. Desconocemos el oficio desempeñado por los tres hermanos porque probablemente no ocuparan cargo en la Casa de don Carlos si no como entretenidos acogidos por el Duque de Alba que prácticamente venía ejerciendo sobre ellos una tutela paternal debido a su orfandad (Martínez Hernández, 2004a: 71).

También fue su tío, el duque de Alba, quien le introduce en la Academia que él mismo promueve, donde se dan cita un grupo de jóvenes caballeros que en el futuro formarán un cohesionado grupo político. Unos cuantos miembros de esta Academia conseguirán afianzarse en la Corte, fundamentalmente a partir de 1580 (Martínez Hernández, 2004a: 81-99) ${ }^{12}$.

Las relaciones de la casa de Velada ${ }^{13}$ con el clan de los Toledo (duques de Alba de Tormes, condes de Alba de Liste, condes de Oropesa y marqueses de Villafranca) fueron muy estrechas y beneficiosas, amén de verse fortalecidas a través de una estudiada política de matrimonios, de tal forma que se amplió enormemente la influencia social de los Dávila. Así emparentaron con la casa de Medinaceli y de Astorga, ambas con grandeza de España desde el reinado de Carlos V:

La estrategia matrimonial y familiar llevada a cabo por los dos primeros titulares del marquesado de Velada les permitió consolidarse como una más entre las de la mediana nobleza titulada, incrementado considerablemente

12 Son de muy recomendable lectura las páginas (75-124) dedicadas en este trabajo a la Abadía y a la Academia, aquí se hace referencia, entre otros asuntos, a los miembros que formaron la Academia del duque de Alba y se establecen la conexiones entre ellos.

13 Las relaciones con los Toledo y otras familias nobiliarias han sido estudiadas detalladamente por Martínez Hernández, a quien resumo (2004a: 125-187). 
su hacienda, prestigio y consideración política y social, así como incluirse entre las pocas privilegiadas a las que se le concedió la Grandeza (Martínez Hernández, 2004a: 126).

El periodo de mayor esplendor para la casa de Velada llega con el II marqués, Gómez Dávida y Toledo — sucede a su abuelo en el marquesado en 1561 - , responsable de acrecentar la hacienda y lograr el ascenso social y político de la familia, a lo que ayudaron los vínculos y relaciones familiares, pues, tras la muerte del gran duque de Alba (†1582), él ejerció la tutela del linaje y supo sacar ventaja de su posición privilegiada con el clan de los Toledo. Todo esto le condujo a ocupar cargos destacados en la Corte durante los últimos años del reinado de Felipe II y primeros de Felipe III. Fue de enorme transcendencia la labor desempeñada en el oficio de ayo del príncipe Felipe — futuro Felipe III_- ya que, como explica Martínez Hernández (2004a: 255), «iniciar la carrera en palacio en aquellas circunstancias significaba el medio más rápido y seguro para alcanzar un lugar de privilegio en la Corte en breve tiempo». Pero lo que me interesa destacar es que la selección de los criados que sirvieron en la casa del príncipe fue una tarea minuciosa llevada a cabo con el mayor esmero ${ }^{14}$.

El monarca tomó especial cuidado en configurar la casa de su hijo, escogiendo a sus servidores tras una cuidadosa selección en la que la principal condición era no haber pertenecido a facción cortesana alguna, al menos de las vinculadas con las antiguas parcialidades. De este modo los servidores, debían reafirmar su compromiso de fidelidad y servicio con el príncipe, y del mismo modo con el jefe de su casa, el marqués de Velada. (Martínez Hernández, 2004a: 254-255).

La abuela de Quevedo, Felipa de Espinosa abandonó la casa del príncipe antes de la llegada de Velada al oficio de ayo del futuro rey, por lo que podríamos pensar que quizás no la llegó a conocer ${ }^{15}$. Sin embargo sí

14 Entendemos que el mismo cuidado se tuvo que imponer en la selección de todos los criados, desde los de más alto rango a los de menor categoría, por lo que esto afectó tanto a los familiares de Quevedo como al marqués.

15 Felipa de Espinosa sirve al príncipe Felipe durante el periodo en el que Cristóbal de Moura es sumiller de corps de su padre, el rey Prudente, y Juan de Zúñiga, preceptor del heredero al trono. 
coincidió, a partir del momento en el que se hace cargo de la educación del joven Felipe, con María de Santibáñez, puesto que tras enviudar ésta, en 1586, pasó a vivir en palacio como dueña de la reina doña Ana. Aunque las fechas no encajen en ambos casos, tenemos la certeza de que el marqués tuvo conocimiento de las dos, a las que tuvo en gran estima por su calidad y virtud, según atestigua un antiguo criado de palacio de más de 100 años en el expediente de ingreso de Francisco de Quevedo en la Orden de Santiago:

Dixo este testigo tiene más de çien años, i que de muchos a esta parte conoçe a don fran[cis]co de quebedo, i conoció a su madre que llamaban doña maría de Santibáñez, i a su abuela materna llamada doña filipa despinosa i rueda [...], eran Personas de mucha estimaçion i bien queridas, y ningunas en la casa real en tiempo Suio lo fueron más, i esto lo oió a el marq[u]és de belado [sic] muchas beçes este testigo hablando de la santidad y birtud y buenas Partes de las dichas madre i abuela del pre[tendien]te, y de su calidad ni más ni menos oio hablar mui bien a el dicho marq[u]és que hacía oficio de maiordomo maior, diciendo que eran las dichas Señoras Personas mui bien nacidas (Riandière, 1986: 105-106).

También tuvo que saber el marqués de Pedro Gómez de Quevedo, el padre del escritor, quien fue uno de los criados al servicio de la casa del príncipe don Carlos en los mismos años que él entró con sus hermanos, por mediación del duque de Alba, en la casa de dicho príncipe. De igual manera tuvo que conocer al marido de su tía Margarita y a los hermanos de aquel, puesto que todos desempeñaron diferentes papeles al servicio de la casa del rey Felipe II. Finalmente recordemos que Quevedo tuvo que vivir con su madre en el alcázar entre 1586 y 1594 —en este año se traslada a estudiar a Ocaña - y que Antonio Sancho Dávila nace en 1590, aunque en ese lapso temporal es improbable que se produjese ningún contacto de interés entre ellos. Pero sin duda, el heredero del marquesado, pasado el tiempo, al igual que su padre, tuvo que saber bien quienes eran los Santibáñez, Espinosa, Villegas y Santoyo y cuál era la facción en la que podía ubicar al escritor y a su familia ${ }^{16}$.

Muerto Felipe II, la situación para los antiguos criados del rey cambia de forma considerable, una buena parte de ellos fueron sustituidos por 
hombres de confianza del favorito del nuevo monarca, el marqués de Denia, y Gómez Dávila, aunque se mantuvo en el oficio de mayordomo mayor de Felipe III, tuvo que aprender a sortear las trabas que Sandoval y Rojas puso a su ascenso social y político, solo logrado cuando el privado vio disminuir su influencia sobre el rey. Entonces y solo entonces, el marqués de Velada alcanza la muy ansiada grandeza de España. Para esta época las pasadas buenas relaciones con el conde de Olivares se resquebrajan y el distanciamiento entre ellos cada vez es mayor ${ }^{17}$.

La muerte de Felipe III sorprende a Antonio Sancho Dávila en circunstancias poco halagüeñas. De su padre no solo había recibido hacienda y títulos, también había heredado a sus enemigos — los Sandovales-, en concreto al de Uceda, quien veía en él un peligroso rival. Además el III marqués de Velada pasó los años últimos del reinado de Felipe III desterrado de la Corte - fue perdonado por el rey unos días antes de fallecer-, lo que no le ayudó a establecer alianzas con la nobleza opositora a Uceda ${ }^{18}$. Todo esto unido a la animadversión de Olivares hacia los Toledo, obliga a don Antonio a alejarse de la Corte para poder en un futuro medrar en ella. Olivares se deshace de la presencia de Velada en Madrid en el año 1625 , pero la decisión de su marcha se toma justo antes de la jornada real a Andalucía de 1624, de la que el grande de España quedó excluido:

Me mandó S. M. en el año de 624 antes de partir para la Andaluzia, que me previniesse para el cargo de Capitan General en Oran, y que se me mandaria ir el año siguiente (como se executó) y servi el dicho puesto dos años y medio obrando prudençialmente (Alonso Acero, 2000: 58-59).

También sabemos por su hoja de servicios, enviada a don Luis de Haro en 1644, que antes de ese viaje real solicitó a Olivares, en una conversación mantenida con él en El Pardo, que intercediese ante el rey para poder disfrutar de la merced de su encomienda ${ }^{19}$, y allí recuerda otra vez que es el conde duque quien le marca el camino de salida de la Corte:

17 Remito una vez más a Martínez Hernández (2004a: 431-551), quien aborda en profundidad la conflictiva relación que mantuvieron Velada y Lerma, y la causas del desafecto con Olivares (338-340).

18 Martínez Hernández (2004b:160).

19 La encomienda a la que hace referencia en la hoja de servicios manuscrita tiene que ser la de Manzanares de la orden de Calatrava obtenida por su padre del rey Felipe III. 
El año de 24 me dixo el señor conde duque en el Pardo, que puede ser que lo oyese [el] condestable que estaua allí, quando su magestad se disponía para hir a la Andalucía, suplicándole yo intercediese con su magestad para que me hiciese merced de mi encomienda [...] que dilatase esta pretensión asta que hi[ciese] algún seruicio a su magestad fuera de España, para entonces él me ayudaría con muchas [...?] (BNE, ms. 18171: 128v-129r).

Quevedo se ve en una situación pareja cuando llega al trono Felipe IV, puesto que su participación en las causas contra Osuna le sacaron forzosamente de la Corte, además la caída de los Sandovales y del mismo Osuna le han dejado sin los apoyos de estos grandes y fuera del nuevo mapa político. Para el año de 1624 parece ser que ha hallado acomodo en uno de los grupos nobiliarios que pugna por el favor real, lo que explica que encontremos al escritor en la comitiva de la jornada real a tierras andalu$\mathrm{zas}^{20}$. Sin duda, la carta que dirige a Velada tiene un fin claramente informativo y es plausible pensar que esta carta no fue la única que remitió a la Corte con igual motivo ${ }^{21}$. En ella da noticia de los avatares del viaje y de algunas personas de la comitiva y silencia el nombre de otros, entre ellos, el de Olivares, el personaje más relevante del momento y artífice del viaje, lo que cuesta creer que sea casual ${ }^{22}$. Esta carta hasta el momento ha sido sometida a una interpretación meramente burlesca y jocosa. Mas considero que la correcta identificación y ubicación en las facciones cortesanas de cada uno de los personajes a los que Quevedo mencionada son una labor que contribuye a una lectura de la carta con una perspectiva política y, por tanto, a la postre nos va a permitir colocar a Quevedo en el lugar que le corresponde en el tablero cortesano durante la privanza de Olivares.

La nómina de personas citadas es la siguiente: el almirante de Castilla, don Enrique Enríquez, el cochero, Felipe IV, Gaspar de Bonifaz, los regidores de Manzanares, el «Caballero de la Tenaza», Miguel de Cárdenas, el conde de Santisteban, unos caballeros de Úbeda y Baeza, Gaspar de

20 Sobre esto véase Pérez Cuenca y Campa Gutiérrez (2017).

21 Esto podemos deducirlo del párrafo último de la respuesta de Velada a Quevedo: «Andrés, aquel anochecido de rostro, tan Mendoza por línea curva como mulato por línea recta, ha enviado aquí quejas de que vuesa merced escribe las nuevas sin su licencia» (Quevedo, 1946: 121). Actualmente estoy trabajando en colaboración con Mariano de la Campa en el estudio y edición crítica de la carta de Quevedo y la respuesta de Velada.

22 Sobre esto apunto algunas ideas en Pérez Cuenca (2018: 205-209) que se desarrollarán con detalle en un próximo estudio. 
Tebes, Mateo Montoro, Vargas, Alonso Gutiérrez Grimaldo ${ }^{23}$, Francisco de Morovelli, Juan de Arana, Andrés de Almansa y Mendoza, Francisco de Zapata (caballerizo del rey), el duque del Infantado, el patriarca de las Indias, el marqués del Carpio, Garci Pérez de Araciel y Hortensio de Paravicino. No es posible estudiar aquí uno a uno a cada personaje, pero sí que podemos avanzar que alguno de ellos han optado por adaptarse a los nuevos tiempos que corren y situarse al lado de Olivares - como Infantado y Santisteban - , mientras que otros, por el contrario, aunque participen en la jornada, se colocan abiertamente en el bando opositor. Así sucede con el almirante de Castilla, quien cede su coche a Quevedo y acompañantes, contrario a Olivares desde su llegada al poder, lo que años después de este viaje le pasará cara factura ${ }^{24}$. No es diferente el caso de Enrique Enríquez ${ }^{25}$, a quien propongo que se le identifique con el VII conde de Alba de Liste, don Enrique Enríquez de Alba, otra rama del clan Alba, enfrentado también al privado de Felipe IV. Del otro lado, tenemos a Gaspar de Bonifaz, quien asciende social y velozmente desde la llegada al trono del rey Planeta, y al ya mencionado Santisteban ${ }^{26}$, ambos objeto de los dardos satíricos quevedianos.

Como se ha intentado resaltar, el proceso de descubrir las redes clientelares que se tejen durante la privanza de Olivares y conectar en la facción correspondiente a los clanes nobiliarios y familias que durante años estuvieron al servicio de las casas reales, al tiempo que se revelan las conexiones de Francisco de Quevedo — sin olvidar las de sus familiares - nos abre ventanas que contribuyen a una nueva interpretación de buena parte de sus escritos, comenzando por su epistolario pendiente aún de una rigurosa edición.

23 La identificación de Grimaldo ha sido posible gracias al vejamen de Antonio Hurtado de Mendoza estudiado y editado por Madroñal (2005: 279).

24 Sobre Quevedo, el almirante de Castilla y Velada véase Pérez Cuenca y Campa Gutiérrez (2017: 1953-1959); también léase Martínez Hernández (2016: 67 y ss) para el Almirante de Castilla y su enfrentamiento con Olivares.

25 Deleito y Piñuela (1988: p. 282, n. 88) identificó a este personaje con Juan Alonso Enríquez de Cabrera, Almirante de Castilla, dueño del coche en el que viaja el escritor.

26 Para Bonifaz remito a Valiñas (2018) y Pérez Cuenca (2018: 225-229); para Santisteban véase Martínez Hernández (2016: 67 y ss). 


\section{BIBLIOGRAFÍA}

Alonso Acero, Beatriz, Orán-Mazalquivir, 1589-1639: Una sociedad española en la frontera de barbería, Madrid, CSIC, 2000.

Baltar Rodríguez, «Los Villanueva: Un linaje aragonés al servicio de la Monarquía. Apuntes sobre su asentamiento en la Corte de los Austrias», en Gonzalo Martínez Díez, Ignacio Ruiz Rodríguez (coords.), Universitarios y personajes ilustres de la Corona de Aragón y su papel en la construcción de España y el Nuevo Mundo. Actas del «I curso de verano Ciudad de Tarazona», Madrid, Dykinson, 2000, pp. 79-95.

Crosby, James O. y Pablo Jauralde Pou, Quevedo y su familia en setecientos documentos notariales (1567-1724), Madrid, Universidad Autónoma de Madrid, 1992.

Deleito Piñuela, José, El rey se divierte, Madrid, Alianza, 1988.

Diccionario biográfico español, Madrid, Real Academia de la Historia, 2018, accesible en línea: <http://dbe.rah.es> [consultado el 15.09.2018].

López Ruiz, Antonio, Tras las huellas de Quevedo (1971-2006), Almería, Universidad, 2008.

Madroñal, Abraham, «De grado y de gracias». Vejámenes universitarios de los siglos de oro, pr. de Aurora Egido, Madrid, CSIC, 2005.

Martínez Millán, José, «Reflexiones en torno a los escritos políticos e históricos de Francisco de Quevedo», La Perinola, 18, 2014, pp. 103-141.

Martínez Millán, José e Ignacio Ezquerra Revilla, «La integración de las élites sociales en las monarquías dinásticas. Los continos», en Jesús Bravo (ed.), Espacios de poder: Cortes, ciudades y villas (S. XVI-XVIII), Madrid, J. Bravo, 2002, vol. 1, pp. 339-380.

Martínez Millán, José y José Eloy Hortal Muñoz (dirs.), La Corte de Felipe IV (16211665). Reconfiguración de la monarquía católica, Madrid, Polifemo, 2015, t. II en CDRom.

Martínez Millán, José y Koldo Trápaga Monchet, «La transformación institucional de la cámara real de la Monarquía hispana durante el siglo XVII», en José Martínez Millán y José Eloy Hortal Muñoz (dirs.), La Corte de Felipe IV (1621-1665). Reconfiguración de la Monarquía católica, Madrid, Polifemo, 2015, t. I, vol. 1, pp. 317-439.

Martínez Millán, José y Ma Antonietta Visceglia, (dirs.), La monarquía de Felipe III. La casa del rey, Madrid, Fundación Mapfre, Instituto de Cultura, 2007-2008, 2 vols.

Martínez Millán, José y Santiago Fernández Conti, (dirs.), La monarquía de Felipe II. La casa del rey, Madrid, Fundación Mapfre-Tavera, 2005, 2 vols.

Martínez Hernández, Santiago, Don Gómez Dávila y Toledo, II Marqués de Velada, y la Corte en los reinados de Felipe II y Felipe III, (1553-1616), [Valladolid], 
Junta de Castilla y León, Consejería de Cultura y Turismo, 2004a. [Tesis doctoral: Madrid, Universidad Complutense, 2002, accesible en línea: <http://eprints.ucm. es/4607> [consultado el 15.09.2018].

Martínez Hernández, Santiago, «Aristocracia y gobierno: aproximación al cursus honorum del Marqués de Velada, 1590-1666», en Francisco José Aranda Pérez (coord.), La declinación de la monarquía hispánica en el siglo XVII. Actas de la VII ${ }^{a}$ Reunión Científica de la Fundación Española de Historia Moderna, Cuenca, Castilla-La Mancha, 2004b, pp. 155-167.

Martínez Hernández, Santiago, «La cámara del rey durante el reinado de Felipe IV: Facciones, grupos de poder y avatares del valimiento (1621-1661)», en Rafael Valladares (ed.), pr. de John H. Elliott, El mundo de un valido. Don Luis de Haro y su entorno, 1643-1661, Madrid, Marcial Pons, 2016, pp. 49-96.

Pérez Cuenca, Isabel, «Francisco de Quevedo y el VII duque de Medinaceli: Cajón de sastre noticiero», en Antonio Rey Hazas, Mariano de la Campa Gutiérrez y Esther Jiménez Pablo (eds.), La Corte de Barroco. Textos literarios, avisos, manuales de Corte, etiqueta y oratoria, Madrid, Polifemo, 2016, pp. 169-264.

Pérez Cuenca, Isabel, «Esbozos de retratos en las cartas de Francisco de Quevedo», La Perinola, 22, (2018), pp. 201-246.

Pérez Cuenca, Isabel y Mariano de la Campa Gutiérrez, «Algunas consideraciones sobre Quevedo y Olivares. Una revisión historiográfica», en José Martínez Millán, Manuel Rivero Rodríguez (dirs.), La Corte de Felipe IV (1621-1665). Reconfiguración de la Monarquía católica. Espiritualidad, literatura y teatro, Madrid, Polifemo, 2017, t. III, vol. 3, pp. 1949-2012.

Quevedo, Francisco de, Epistolario completo, ed. crítica de Luis Astrana Marín, Madrid, Instituto Editorial Reus, 1946.

Quevedo, Francisco de, Carta escrita al marqués de Velada en la jornada que hizo el rey a Sevilla, en febrero de 1624, en Prosa festiva completa, ed. de Celsa Carmen García-Valdés, Madrid, Cátedra, 1993, pp. 379-388.

Quevedo, Francisco de, Nuevas cartas de la última prisión de Quevedo, estudio, ed. crítica y anotaciones de James O. Crosby, Woodbridge, Tamesis, 2005.

Quevedo, Francisco de, Cartas a Sancho de Sandoval (1635-1645), ed. de Mercedes Sánchez Sánchez, Madrid, Calambur, 2009.

Rabasco Ferreira, Rafael, La representación pontificia en la Corte española. Historia de un ceremonial y diplomacia, Madrid, Sanz y Torres, 2017.

Riandière la Roche, Josette, «Expediente de ingreso en la Orden de Santiago del caballero D. Francisco de Quevedo y Villegas. Introducción, edición y estudio», Criticón, 36, (1986), pp. 43-129.

Riandière la Roche, Josette, Nouveaux documents quévédiens. Une famille à Madrid au temps de Phiulippe II, pr. d'Augustin Redondo, Paris, Publications de la Sorbonne, 1992. 
Riandière la Roche, Josette, «Le favori dans quelques oevres politiques et pamphelets de Quevedo», en Hélène Tropé (coord.), La représentation du favori dans l'Espagne de Philippe III et de Philippe IV, Paris, Presses de la Sorbonne Nouvelle, 2010, pp. 75-109.

Tarsia, Pablo Antonio, Vida de don Francisco de Quevedo y Villegas, repr. facs. [de la ed. Madrid, Pablo de Val, 1663] cuidada por Melquiades Prieto Santiago, pr. de Felipe B. Pedraza Jiménez, Aranjuez, Ara Iovis, 1988.

Valiñas, Sandra, «Gaspar Bonifaz bajo la óptica de Quevedo», La Perinola, 22, (2018), pp. 377-410.

\section{ANEXo}

\section{A. Oficios ejercidos por familiares de Francisco de Quevedo ${ }^{27}$}

\section{PADRES Y HERMANOS}

Pedro Gómez de Quevedo, el Mozo (†1586): Padre de Quevedo. Secretario de la emperatriz María en Alemania. Repostero de $\operatorname{camas}^{28}$ y guardadamas de la reina doña Ana, puesto que desempeñó su suegro. Escribano de la cámara del príncipe don Carlos. En 1578 es nombrado escribano de la reina doña Ana gracias a la intermediación de Felipa de Espinosa, su suegra. En 1583 consigue el oficio de secretario del príncipe Felipe (futuro Felipe III), antes lo fue de las infantas. Estuvo a cargo de ordenar las cuentas y la sucesión de Bartolomé Murga, tesorero de la emperatriz María, prueba de la confianza que disfrutaba en la casa real.

María de Santibáñez (†1600): Hija de Juan Gómez de Santibáñez Ceballos y de Felipa de Espinosa. Madre de Quevedo. Casó con Pedro Gómez de Quevedo, el Mozo, quedó viuda en 1586; tuvo cinco hijos: Pedro, María ( $† 1578)$, Francisco, Felipa, Margarita y María. Fue dueña de la infanta Isabel Clara Eugenia. Residió en palacio desde que enviudó, entonces fue recibida como

27 Los datos que aquí se ofrecen son una síntesis de la información registrada en Tarsia (1988), Riandière (1986, 1992, 2010), Crosby y Jauralde (1992), López Ruiz (2008) y Martínez Millán y Fernández Conti (2005).

28 Repostero de camas: A su cargo está el cuidar de la puerta de la antecámara de la reina y mullir los colchones de la cama (Diccionario de Autoridades). 
dueña por la reina doña Ana en recompensa por los servicios prestados a la monarquía por sus padres. En 1599 era azafata y dueña de retrete ${ }^{29}$ de la reina Margarita de Austria ${ }^{30}$.

Pedro (n. 1577-†1591): Hermano de Quevedo: Muere con 14 años, hijo primogénito. Su madre consigue para él, cuando tiene 11 años, en 1588, el puesto de escribano de cámara que tenía su padre, cargo que subarrienda por no poder desempeñarlo a causa de su corta edad.

María (†1578): Menina de la infanta.

Felipa (n.1583): Monja carmelita descalza.

Margarita: Menina de la infanta Isabel a los 9 años. Se casa con Juan de Alderete, tiene dos hijos Pedro y Juan.

\section{FAMILIA MATERNA}

Gonzalo de Rueda: Padre de Felipa de Espinosa (abuela materna de Quevedo). Aposentador y guardadamas ${ }^{31}$ de la princesa de Portugal, doña Juana de Austria, hermana de Felipe II, esposa del príncipe don Juan y madre del rey don Sebastián de Portugal.

Juan Gómez de Santibáñez Ceballos (†1576): Abuelo materno de Quevedo, casado con Felipa de Espinosa. Probablemente, desde 1548, fue repostero de camas. Fue uno de los criados predilectos de la emperatriz María, quien pidió a Felipe II una plaza de contino en la casa de la reina Ana para Gómez de

29 Azafata: Oficio de la casa real que sirve una viuda noble, la cual guarda y tiene en su poder las joyas y vestidos de la reina, entra a despertarla con la camarera mayor y una señora de honor, llevando en el azafate el vestido y demás cosas que se ha de poner la reina, que va dando a la camarera mayor, que es quien la sirve. Dueña de retrete: En palacio, las dueñas de segunda clase que, a diferencia de las de honor, cuidaban de las puertas del retrete (Diccionario de Autoridades).

30 Según Tarsia (1988: p. 7), asístió «desde sus tiernos años a la cámara de la reyna».

31 Aposentador estaba a cargo de la furriera y dependía del mayordomo mayor. Entre sus funciones estaba la de tener siempre una silla disponible para, en este caso, la princesa, o levantar su tabla en las comidas en público, lo que le obligaba a estar presente en todas las ceremonias; era su responsabilidad la limpieza de la casa, velar por el estado y acomodo del mobiliario, la provisión del carbón y la leña. En definitiva, era un cargo que suponía una gran cercanía con la hermana de Felipe II. Las atribuciones de este cargo son descritas detalladamente en Rabasco Ferreira (2017: 264-265). El de guardadamas era un empleo honorífico, consistente en ir a caballo en el estribo del coche de las damas para que nadie pueda hablarlas; también les toca despejar la sala de audiencias (Diccionario de Autoridades). 
Santibáñez. Viajó a Austria con la emperatriz Ana como escribano de cámara. Desempeñó también los cargos de guardadamas de la reina doña Ana a partir de 1570 y el de aposentador de Palacio.

Felipa de Espinosa (†1597): Casada con Juan Gómez de Santibáñez Ceballos de quien queda viuda en 1577. A la muerte de su esposo entra como dueña al servicio de la reina doña Ana; se traslada a vivir a Palacio. Azafata de la reina doña Ana, de la infanta Isabel Clara Eugenia y después del príncipe Felipe (1578-1585, futuro Felipe III). Obtiene del rey Felipe II diversas pensiones para sus familiares. Pariente de los Montero de Espinosa y del obispo de Canarias, Fernando de Rueda.

Margarita de Espinosa: Hija de Juan Gómez de Santibáñez Ceballos y de Felipa de Espinosa, hermana de María de Santibáñez, tía de Quevedo. Se casó con Juan de Santoyo y Nevares en 1587, tuvieron un hijo llamado Francisco Nevares Santoyo. Fue doncella de la infanta Isabel Clara Eugenia.

Juan de Santoyo Nevares $(\uparrow 1596)^{32}$ : Contrajo matrimonio con Margarita de Espinosa en 1587, tuvieron un hijo llamado Francisco Nevares Santoyo. Ayuda de cámara de la casa de Borgoña, al menos desde 1588 y hasta 1598. Se jubiló tras la muerte de Felipe II. Disfrutó de la escribanía mayor de rentas de Canarias. Fue hijo de Francisco Santoyo, contino y contador de la cruzada. Sus hermanos fueron Juan Ruiz de Velasco, Sebastián de Santoyo y Francisco Santoyo, todos de la cámara del rey.

Sebastián de Santoyo: De la cámara del rey y padre de Francisco de Nevares, escribano real de las rentas reales de la ciudad de Sevilla y su obispado y también del obispado de Cádiz.

Juan Ruiz de Velasco: Hermano de Juan Santoyo de Nevares y, por tanto, cuñado de Margarita de Espinosa, tía de Quevedo. Ayuda de cámara de Felipe II, al menos desde 1585 hasta 1598. Secretario de la reina en 1598 y del rey Felipe III en 1603.

Francisco Santoyo: Padre de Juan Ruiz de Velasco, Sebastián de Santoyo, Francisco de Santoyo y Juan Santoyo de Nevares. Fue contino de Castilla, desde el 2 de octubre de 1554 hasta su muerte, en mayo de 1594. Fue contador de la cruzada y asimismo contador al servicio de María de Austria, reina de Bohemia, con la que fue a Alemania, en su casa llegó a controlador.

32 Para los Santoyo véase, además de Crosby y Jauralde (1992), Martínez Millán y Fernández Conti (2005: II, 421). 
Pedro de Santoyo: Contino de Castilla desde 1558 hasta 1562, cuando pasó al oficio de mayordomo y pagador de las obras del alcázar de Madrid. Hermano de Sebastián de Santoyo, éste ayuda de cámara de la casa de Borgoña, al menos en 1573, quien fue también pagador de las obras del Bosque de Segovia.

Diego de Santoyo: Costiller de la casa de Borgoña, hasta el 11 de noviembre de 1588, cuando promocionó a gentilhombre de la casa, oficio que conservaba en 1596. No se señala ningún parentesco directo con los anteriores Santoyos.

Bartolomé de Santoyo: El primer ejercicio lo realizó en la casa de Borgoña del príncipe entre 1554 y 1556. Fue ayuda de cámara de la casa de Borgoña desde 1556 hasta 1573 al menos. En el año 1584 era guardajoyas. No se señala ningún parentesco directo con los anteriores Santoyos.

\section{FAMILIA PATERNA}

Lope de Villegas: Padre de María Sanz de Villegas, bisabuelo paterno de Quevedo.

María Sanz de Villegas: Abuela paterna de Quevedo, casada con Pedro Gómez de Quevedo, el Viejo. Pariente cercana de Ana Díez de Villegas, mujer de Agustín de Villanueva.

Pedro Gómez de Quevedo, el Viejo: Abuelo paterno de Quevedo. Elegido alcalde de los hijosdalgos de la comarca; familiar del santo oficio.

\section{B. Cronología:}

\section{Oficios y mercedes de los II y III marqueses de Velada}

\section{Marqués de Velada, Gómez Dávila y Toledo (1541-1616) ${ }^{33}$}

Ayo del príncipe Felipe - futuro Felipe III-. Miembro del Consejo de Estado y de Guerra con Felipe II. Mayordomo mayor de Felipe III y, en su reinado, miembro del Consejo de Estado y de Guerra. Grande de España.

1553: Entra a servir a la casa del príncipe don Carlos, heredero de Felipe II.

Posteriormente rechaza, en dos ocasiones, convertirse en gentilhombre de su cámara, a petición de don Carlos.

1570: Tras la jornada real a Andalucía decide retirarse a sus estados.

33 Toda la información sobre el II marqués de Velada es una síntesis realizada a partir de la tesis doctoral de Martínez Hernández (2002). 
1582: Enviado como representante de Felipe II al concilio provincial de Toledo.

1561: Hereda el título y las responsabilidades que este conlleva, al fallecer el I marqués de Velada, su abuelo, título que otorgó a este Felipe II en el año 1557. Quedó bajo la tutela de su madre hasta alcanzar la mayoría de edad.

1567: El príncipe don Carlos le propone ser gentilhombre de su cámara. Este ofrecimiento lo hará en dos ocasiones, ambas veces rechaza aceptar el oficio. En 1568 don Carlos es encarcelado y fallece. Tras este percance, no se integra en ninguna otra casa real.

1568-1586: Permanece en sus estados sin desempeñar oficio alguno en la Corte.

1587: Es nombrado por Felipe II ayo del príncipe Felipe [III]. Este cargo codiciado por otros no es deseado por Gómez Dávila, quien tiene considerables recelos antes de aceptar. Tiene gran interés en que aceptase Cristóbal de Moura (futuro marqués de Castel Rodrigo) quien, junto a Juan de Zúñiga, Diego Fernández de Cabrera (conde de Chinchón), el archiduque Alberto de Austria, Juan de Idiáquez y Mateo Vázquez, formaría el restringido consejo privado de Felipe II; este grupo se disuelve de forma inmediata tras la muerte del rey en 1598. Velada, desde que es nombrado ayo del príncipe, dispone de aposentos en el alcázar de Madrid y en todas las demás residencias reales, Por orden expresa del rey, supervisaba todas las actividades del príncipe, le limitaba el acceso de los cortesanos y se encargaba de su educación. También se ocupó del buen funcionamiento de la casa de la infanta Isabel Clara Eugenia. Durante los años iniciales en el oficio de ayo se produjeron los primeros enfrentamientos con el marqués de Denia, futuro duque de Lerma, privado de Felipe III.

1590: Es bautizado su hijo y heredero Antonio Sancho Dávila. Los padrinos fueron el príncipe Felipe y Vitoria Colonna, condesa de Melgar, nuera del Almirante de Castilla y prima hermana del marqués. Este fue el primer acto público del heredero de la corona en su papel de príncipe, lo que ha de interpretarse como una clara muestra de reconocimiento y confianza a Velada por parte del rey Felipe II.

1593: Entra en el consejo de Estado y Junta de Gobierno con el príncipe Felipe. A partir de este año, aumenta la influencia del marqués en el entorno más cercano del rey, esto se manifiesta cuando consigue situar a un hombre de su confianza, el padre Pedro Fernández, en el puesto de confesor del príncipe.

1595: Su hija doña Antonia entra al servicio de la infanta Isabel. En este año, empeoran las relaciones con el que fue compañero y amigo en la Academia del duque de Alba, el conde de Olivares, con el que ya se había distanciado 
durante la embajada de Roma y el virreinato de Sicilia del conde. Felipe II concede a Velada el hábito de caballero de la orden de Calatrava y el disfrute de la encomienza de Manzanares.

1598: Muerto Felipe II el marqués es de los pocos que mantienen su preponderancia por deseo del rey Felipe III. Se integra en su Consejo de Estado y se mantiene en su oficio de su mayordomo mayor. A partir de este momento la labor de Velada queda supeditada al duque de Denia, Francisco de Sandoval y Rojas, quien en los años de su ascensión en la privanza frenará sus aspiraciones de grandeza. Familiares y hechuras de Velada consiguen mercedes y favores reales, entre ellos, su hija menor, Antonia de Toledo y Colonna, la cual fue nombrada dama de la reina Margarita, y su hijo, Antonio Sancho, menino y bracero de la reina doña Ana.

1614: Recibe la ansiada grandeza, además también recibió del rey un nuevo título y la permanencia de la encomienda de Manzanares para su hijo.

\section{Marqués de Velada, Antonio Sancho Dávila \\ TOLEDo y COLONNA (1590-1666) $)^{34}$}

Nació en 1590 en el alcázar de Madrid. Apadrinado por el príncipe Felipe [III] y la condesa de Melgar. I marqués de San Román. Menino y bracero de la reina; gentilhombre de la cámara del rey Felipe III. Grande de España. Sus hijos Antonio Pedro Gómez Dávila y Bernardino de Velasco Dávila Osorio también fueron gentilhombres de la cámara del rey.

1599: Menino y bracero de la reina doña Ana.

1610: Gentilhombre de la cámara de Felipe III.

1614: Contrae matrimonio con Constanza Osorio, hermana del marqués de Astorga. Felipe III le concede el título de marqués de San Román y le confirma el disfrute de la encomienda de Manzanares de la orden de Calatrava a la muerte de su padre.

1616: Muere su padre, lo que trae consigo la hostilidad declarada del duque de Uceda.

1619: Fue atacado por cuatro o cinco hombres que lo acuchillaron y mataron a su acompañante durante la jornada de Portugal.

34 La cronología del III marqués la suspendemos en el año 1645, cuando muere Francisco de Quevedo. 
1621: Fue desterrado por Felipe III, el destierro no fue levantado hasta poco antes de morir el monarca. El alejamiento de la Corte provocó que a la muerte del rey quedase al margen de las alianzas orquestadas por los rivales de Uceda.

—- Asistió a las academias del conde de Saldaña y la Peregrina de Madrid.

1623: Participó en la visita del príncipe de Gales y el duque de Buchkingham.

1624: Durante el desarrollo de la jornada de Felipe IV a Andalucía permanece en la Corte.

1624: Nombrado gobernador y capitán general de Orán. Allí permanecerá desde 1625 hasta 1628.

1628-1636: Regresa a la Corte. Periodo de inactividad. Son varias las acciones militares que se le encomiendan durante estos años, pero siempre son suspendidas antes de iniciarse por razones diversas.

1636: Va a Flandes destinado al tercio que fue del Marqués de Celada. Aquí se labró una magnífica reputación. Fue maestre de Campo General en Flandes. Estuvo a cargo de la Armada de Flandes por orden del cardenal infante, Fernando de Austria.

1640: Fue enviado a Londres como embajador extraordinario, donde contó con el apoyo de Malvezzi.

1641: Regresa a Flandes como maestre de Campo General; tras la muerte del cardenal infante se encargó de la Caballería y fue designado segundo de los gobernadores, por encima de él, estaba solo Francisco de Melo, entonces gobernador general interino.

1643-1646: Felipe IV le nombra gobernador y capitán general de Milán. 